serum levels of cholesterol, LDL cholesterol and atherogenic index only showed association with reclassification in controls. The effect of each factor associated with reclassification in patients and controls was compared by the addition of interaction factors in the regression model. In this sense, age (beta coef 2.74 [IC95\% 1.34-5.62] in controls vs. beta coef $0.63(95 \% \mathrm{Cl} 0.40-0.99)$ in patients, interaction $\mathrm{p}=0.001)$ and serum LDL cholesterol levels (beta coef 1.03 [IC95\% 1.02-1.04] vs. beta coef 1.00 [0.99-1.01], interaction $\mathrm{p}=0.002$ ), cholesterol and atherogenic index, showed a greater effect in controls than in patients. The reclassification in patients with a-SpA was associated with a higher ASDAS-PCR $(2.2 \pm$ 1.0 VS. $2.5 \pm 1.0, p=0.041)$, BASFI (3 [1-5] vs. 4 [2-7], $p=0.000$ ) and BASMI scores (2 [1-4] vs. 4 [2-5], $p=0.000)$. However, these differences were lost when they were analyzed adjusting for CV risk factors.

Conclusion: Patients with a-SpA are more likely to be reclassified into very high-risk after carotid ultrasound compared to controls. Traditional CV risk factors have less effect on this reclassification in patients than in controls. The activity, functionality and metrology scores of the a-SpA have a univariate positive relationship with this reclassification.

Disclosure of Interests: Juan Carlos Quevedo-Abeledo: None declared, Javier Rueda-Gotor: None declared, Fernanda Genre: None declared, Alfonso Corrales: None declared, Vanessa Hernández-Hernández: None declared, Esmeralda Delgado-Frías: None declared, Sonia Peña Montelongo: None declared, Carlos Rodríguez-Lozano: None declared, Miguel A González-Gay Grant/research support from: Prof. MA Gonzalez-Gay received grants/research supports from Abbvie, MSD, Jansen and Roche., Speakers bureau: Consultation fees/participation in company sponsored speaker's bureau from Pfizer, Lilly, Sobi, Celgene, Novartis, Roche and Sanofi., Iván Ferraz-Amaro: None declared

DOI: 10.1136/annrheumdis-2019-eular.3746

\section{AB0731 RATE OF SACROILIITIS RADIOGRAPHIC PROGRESSION IN MALE AND FEMALE PATIENTS WITH EARLY AXIAL SPONDYLOARTHRITIS}

Daria Rumiantceva, Tatiana Dubinina, Anastasiya Demina, Shandor Erdes. V.A. Nasonova Research Institute of Rheumatology, Moscow, Russian Federation

Background: According recent studies radiographic progression (mSASSS) of male patients (pts) with ankylosing spondylitis (AS) higher than in female pts [1, 2].

Objectives: to compare radiographic progression of early axial spondyloarthritis (axSpA) in male and female pts over 2 years (y) of follow-up (FUP).

Methods: The research included 68 pts with early axSpA (ASAS criteria, 2009) from Moscow CORSAR cohort with disease duration $<5$ and age onset $<45$ years. The mSASSS index is not suitable for assessing radiographic progression at an early stage of axSpA, because at that stage of the disease, the cervical and lumbar spine have practically no damage. Sacroiliac joints (SIJ) radiographs and CRP performed at baseline and after 2 y FUP. Radiographic SIJ stages scored according to the modified New York criteria grading system. To assess the progression in SIJ, total stage of sacroiliitis (TSS) calculated, by determining sum score stages of sacroiliitis (SI) in the left and right SIJ (from 0 to 8 points). The following formula used to calculate the rate of $\mathrm{SI}$ radiographic progression:

Rate of SI radiographic progression $=\frac{\left(\mathrm{TSS}^{2}-\mathrm{TSS}^{1}\right) \times 12}{\mathrm{FUP}}$

${ }^{*}$ TSS $^{1}$ - initial total score stages of SI, TSS ${ }^{2}$ - FUP total score stages of $\mathrm{SI}$

Pts mean age was $28,5(5,8)$ y, average disease duration - $24,1(15,4)$ mo, $63(92,6 \%)$ pts were HLA-B27 positive.

Results: Initially, among men there were more pts with AS than among women and they had a higher TSS and higher CRP level (table 1). Rate of $\mathrm{SI}$ radiographic progression in male and female pts with axSpA at baseline did not differ.
Abstract AB0731 Table 1.. Outcome parameters at baseline.

\begin{tabular}{lccc}
\hline & Men $(\mathrm{n}=33)$ & $\begin{array}{c}\text { Women } \\
(\mathrm{n}=35)\end{array}$ & $\mathrm{p}$ \\
\hline Ankylosing spondylitis, $\mathrm{n}, \%$ & $25(75,5 \%)$ & $15(42,8 \%)$ & $\mathbf{0 , 0 0 7}$ \\
Non-radiographic axSpA, $\mathrm{n}, \%$ & $8(24,5 \%)$ & $20(57,2 \%)$ & $\mathbf{0 , 0 0 5}$ \\
Total stage of sacroilitis, mediane [IQR] & $4,0[4,0 ; 5,0]$ & $3,0[2,0 ; 4,0]$ & $\mathbf{0 , 0 2 1}$ \\
Rate of SI radiographic progression, mediane & $2,3[1,3 ; 4,0]$ & $2,0[1,0 ; 4,0]$ & 0,364 \\
[IQR] & & & \\
CRP, mediane [IQR] & $12,8[1,7 ;$ & $4,3[0,9 ; 9,8]$ & $\mathbf{0 , 0 4 1}$ \\
& $31,8]$ & & \\
\hline
\end{tabular}

After 2 y FUP, pts with AS still prevailed among men (table 2). TSS increased in both groups: in female pts from $3[2,0 ; 4,0]$ to $4[3,0 ; 4,0]$ $(p<0,05)$, in male pts from $4,0[4,0 ; 5,0]$ to $4[4,0 ; 6,0](p<0,05)$. But, however, in female pts TSS remained less than in male pts over $2 y$ FUP (table 2). CRP level still was higher in male pts $(p<0,05)$. Progression from non-radiographic axSpA to AS between male and female pts didn't differ - $5(15,5 \%)$ vs $6(17,2 \%)$, p $>0,05$ respectively, after 2 y FUP. In both groups rate of $\mathrm{SI}$ radiographic progression after 2 y decreased $(p<0,05)$ and did not differ between them.

Abstract AB0731 Table 2.. Outcome parameters after 2 y of FUP.

\begin{tabular}{lccc}
\hline & Men $(\mathrm{n}=33)$ & $\begin{array}{c}\text { Women } \\
(\mathrm{n}=35)\end{array}$ & $\mathrm{p}$ \\
\hline Ankylosing spondylitis, $\mathrm{n}, \%$ & $30(90,9 \%)$ & $21(60,0 \%)$ & $\mathbf{0 , 0 0 3}$ \\
Non-radiographic axSpA, $\mathrm{n}, \%$ & $3(9,1 \%)$ & $14(40,0 \%)$ & $\mathbf{0 , 0 0 3}$ \\
Total stage of sacroiliitis, mediane [IQR] & $4,0[4,0 ; 6,0]$ & $4,0[3,0 ; 4,0]$ & $\mathbf{0 , 0 0 6}$ \\
Rate of SI radiographic progression, mediane & $0[0 ; 1,0]$ & $0[0 ; 0,5]$ & 0,98 \\
[IQR] & $5,0[1,0 ;$ & $1,2[0,6 ; 4,0]$ & $\mathbf{0 , 0 0 5}$ \\
CRP, Me, [25\%; 75\%] & $12,7]$ & & \\
\hline
\end{tabular}

Conclusion: 1. Rate of $\mathrm{SI}$ radiographic progression in male and female pts with axSpA in the first 2 y from the onset of disease is higher than in further. 2. Rate of $\mathrm{SI}$ radiographic progression between male and female pts with axSpA is not differ. 3. Male pts with AS more than female pts in CORSAR cohort. It can be explained that male pts had higher CRP level than female pts.

\section{REFERENCES}

[1] Baraliakos $X$, et al. The natural course of radiographic progression in ankylosing spondylitis: differences between genders and appearance of characteristic radiographic features. Current rheumatology reports $2011 ; 13$ (5):383.

[2] Rudwaleit, M. et al. The early disease stage in axial spondylarthritis: results from the German Spondyloarthritis Inception Cohort. Arthritis \& Rheumatism: Official Journal of the American College of Rheumatology 2009;60(3):717-727.

Disclosure of Interests: Daria Rumiantceva: None declared, Tatiana Dubinina: None declared, Anastasiya Demina: None declared, Shandor Erdes Consultant for: Development of studies concepts., Speakers bureau: Educational meetings organized or supported by companies.

DOI: 10.1136/annrheumdis-2019-eular.3271

\section{AB0732 THE ASSOCIATION BETWEEN PERIODONTAL DISEASE AND RISK OF ANKYLOSING SPONDYLITIS: A SYSTEMATIC REVIEW AND META-ANALYSIS}

Patompong Ungprasert ${ }^{1}$, Karn Wijarnpreecha ${ }^{2}$, Wisit Cheungpasitporn ${ }^{3} .{ }^{1}$ Faculty of Medicine Siriraj Hospital, Mahidol University, Clinical epidemiology unit, Bangkok, Thailand; ${ }^{2}$ Mayo Clinic Florida, Jacksonville, United States of America; ${ }^{3}$ University of Mississippi Medical Center, Jackson, United States of America

Background: The association between periodontal disease and rheumatoid arthritis is well-recognized [1]. Porphyromonas gingivalis is probably the link between the two conditions. On the other hand, the data on the 